\title{
DESIGNING STUDENT ORIENTED ELEARNING ENVIRONMENTS IN HIGHER EDUCATION TO MATCH TECHNOLOGICAL TRENDS
}

\author{
Chad Manian \\ Department of Business, Faculty of Business and Law, Kaplan Holborn College, London, \\ United Kingdom \\ Kaplan Holborn College, 179-191 Borough High Street, London SE1 1HR \\ Telephone: 02070891712, UK
}

\begin{abstract}
This article briefly examines the impact of prevailing technological trends on student learning and considers the potential role of e-learning technology in establishing learning environments favourable to higher education. The author identifies the noticeable decline in student competence, language/communication skill and research ability as an outcome of emerging social media trend. Research indicates that current trends may pose a challenge to academia in the long-run. The concluding strategies are suggested for establishinge-learning environments that facilitate improvement in student ability within higher education: - 1) incorporating student-centric approach within higher institutions, 2) encouraging culture change among lecturers to create a more e-learning environment, 3) student goalsetting approach in e-learning design 4) adopting onlinestudent portfolios for feedback, 5) implementing a learning strategy using digital media to enforce a learning culture.
\end{abstract}

\section{KEYWORDS}

E-learning, Social Media, Education Strategy, Innovative Teaching

\section{INTRODUCTION}

\subsection{Research objectives}

This articleaddresses 2 objectives:

- To examine the impact of prevailing technological trends on student learning within higher education;

- Critique contemporary theories to formulate astudent-oriented approach to e-learning environmentsfavourable to higher education institutions.

\subsection{Structure of the article}

To address the above aims thearticle begins by providing definitional clarity of key concepts like learning, learning environments, with a brief history of the learning process as a phenomenon driven by dynamic social trends. The paper then proceeds to review e-learningframework within higher education. 
Before an approach to e-learning can be examined it is first necessary to understand and arrive at an acceptable definition of 'learning' which has been the topic of much academic debate. To this extent a review of considerable literature is made, comparing the views of different perspectives. Following this, technological trends within higher education areconsidered along with a discussion of their impact on student learning and performance.

The paper considers student behaviour and performance to be an inevitable outcome of the learning environment. It is also presupposed that learning environments are often the result of prevailing institutionalculture, broader social and technological trends. Consequently, the design of learning environment conducive to optimum performance is mentioned.Finally, to round up based on the above;institution-led strategies are suggested to improve student learning and performance while improving overall student experience for the higher education sector.

\subsection{Definition of Key Concepts}

E-learning is only a form of learning and learning as far as education institutions are concerned can only be said to take place once a learning outcome is reached. Before a discussion on elearning is considered, it is first important to arrive at an agreeable concept of learning in the broadest sense. Learning has been the topic of much research and debate since the 1800s. A variety of disciplines have attempted to define and examine the concept of learning from philosophy, religion and psychology to brain research, neural sciences and other purely scientific fields. Yet despite the scope and extent of research little has been done to directly improve our understanding of learning in order to improve teaching (Biggs and Tang, 1993). For surely, if learning was understood completely it would mean improved teaching and thereby improved student performance.

As a basic starting point the Oxford English dictionary defines learning as the 'acquisition of knowledge or skills through study, experience, or being taught'. A more medical view according to the Merriam-Webster medical dictionary considered learning to be 'the process of acquiring a modification in a behavioural tendency by experience (through conditioning) in contrast to behaviour changes brought about through a temporary physiological condition. This clinical view considers learning to be a long-time permanent change in behaviour brought about through experience. From the perspective of academics who are actively engaged in the process of facilitating learning, the former view is commonly shared. Learning within higher education institutions is considered the transfer of knowledge, skill and assimilation of new ideas which lead to employability.

This paper considers the necessity of considering a range of theories and definitions of learning from an interdisciplinary vantage point. Biggs and Tang (1993 pp. 21) opined that -

'until recently psychologists were concerned with developing One Grand Theory of Learning that covered all learning, rather than with studying the contexts in which people learned, such as schools and universities'.

In order to understand the development of learning theories it is important to trace the origin and history of human learning back to its primal anthropological settings. Early experiments into associative learning by Pavlov (1897) in Russia and Thorndike's (1905) Law of effect sought to deepen our understanding of how learninghappens on the surface. Critics ofearly behaviourism claimed they were too reductive and failed to consider the internal process of individuals.Skinner (1936) introduced the concepts of learning as behaviour modification through conditioning and shaping. 
However, it was not until Bandura (1963) that a theory of social learning combining elements of cognitive and behavioural frameworks emerged. The view that human behaviour is formed through a dynamic interaction with the environment is held byanthropologist. The anthropological perspectivestates that human behaviour is essentially derived from a survival mechanism that needs to adapt and change based on external stimulus. Social anthropologists defend the view that the homo sapiens species as a genus differs from other forms of man in its unique ability to adapt, learn and alter behaviour to suit the environment. The Darwinian model similarly asserts that natural selection precludes that ones with a higher capacity to learn and evolve will likely survive environmental change.The emphasis in all these views is on the environment. Recent studies like Pilikian (2011) affirm that in the early evolution of man it was the environment that determined the level of learning occurrence. Therefore, it is in complex ever changing, 'interesting' environments that learning occurs (Pilikian; 2011). This view strengthens the argument in favour of developing dynamic learning environments that provide complex challenges and opportunities for behaviour change.

\subsection{Brain Pattern, Learned Behaviour and Learning Environments}

Recent insights from cognitive scientists consider learning as a form of information processing, while neuro-linguistic programming (NLP) research and studies by brain researchers, likeNobel winner Gerald Maurice Edelman, propose that thinking and learning involve an on-going process of cerebral pathway building, supporting Gestalt-psychology which drew attention to the importance of pattern and form in perception and learning.Basset (2006) offers a view that the human brain is ideally geared towards habit and has an internal neural geometric configuration that alters based on the learning occurrence. This concept is helpful in understanding the importance of conditioning the mind through repetitive activity. Learning by repetition provides an advantage in forming activity based teaching methodology.

For learning to be permanent it must result in the altered behaviour; acquisition of skill and assimilation of knew information brought about through the formation of new neural pathways (Pilikian; 2011). Recent insights into memory systems by Henke (2010) reveal how neural pathways are formed through synaptic associations occurring within the brain. The pattern of these associations forms the basis of long-term memory. Repetition in this case initiates wiring of neurons into a configuration that over a period of time becomes a permanent pattern. It is this formation that neuro-scientistslike Pellionisz (1989) consider to be true learning.

Research conducted by Cambridge University developmental biologist Rupert Sheldrake (1981) into empathetic learning examined how individuals within indigenous tribal communities learned through observation and social memory. This study considered learning to be the outcome of socialisation using strong individual relationships to be the transfer mechanism in which skills, values, habits, norms and behaviour were transferred. Sheldrake demonstrated how tribal members with strong social ties within a natural environment had similar neural pathways and picked up skills by observing others within the tribe. It was also demonstrated that younger group members showed high levels of mirror neuron activity when they were picking up a new skill by observing an elder. Mirror neurons found at the temples of the forehead are responsible for empathy and stimulated during learning or performing new activities. This view offers a refreshingly different perspective on collaborative learning and neural networks.

If there is indeed a natural process within the human mind that allows for collaborative learning through socialisation, it surely strengthens the case for increased collaboration and use of technology that facilitates or even replicates the same social process. Wheeler and others (2013) conducted research into communities in Australia to examine the benefits of learning through social collaborations. The advent of social media web 2.0 can be considered a modern, technical 
means of bringing individual members of a 'social group' together (Rednecker, 2009). The tribe in this case is formed by students who share similar interests, modules, or undertake the same course and may tend to form strong social ties. Social groups function according to the same dynamics as neural networks. People within a social online community are likely to have similar neural pathways. This is inevitable since they are likely to share similar values, beliefs, behaviours and habits. Socialisation forms an effective means of influence on individuals in a group. Group behaviour will tend to affect and influence the individual (Prechter; 1999).

Conventional behaviourist understanding has led to two different approaches to education. The top-down approach favoured in North America and the bottom-up approach in Europe and Australia - observing students learning in context (Biggs and Tang; 2011). Within the UK higher education sector the emphasis has been on learning based on the achievement of predetermined learning outcomes. The view held by the British quality assurance agency (QAA) emphasises the importance of designing learning environments as an instructional condition to accomplishing educational outcomes.

This idea is essentially superficial and largely ignores the deeper neurological essence of learning and underrates the importance of the learning environment. Authors like Wild, Modritscher and Sigurdarson (2008 pp.2) proved that establishing a learning environment, i.e. a network of people, artefacts and tools involved in learning activities, is part of the learning outcome, not an instructional condition. Their study also considered emergence of behaviour to be an unavoidable and natural phenomenon of complex networks. From a computing perspective - information systems theory considers learning to be a complex process of information assimilation and knowledge transfer through interaction between people, processes, technology, sharing and collaborative networks (Laudon and Laudon, 2012).

This article accepts the scientifically valid notion that all learned behaviour occurs as an outcome of the learning environment. Brain pattern occurs gradually. Long-term neural pathways and their consequent synaptic associations are formed and affected as students engage with and adapt to their environment and therefore a learner-oriented view, placing students at centre stage is necessary.

Having established the definitional basis of learningit is now possible to define learning from an institutional perspective as the achievement of a pre-set learning outcome. Institutions commonly place a high emphasis on achieving targets and set learning outcome statements on a modular, curricular and course level which seek to measure learning through task-based assessments. This is the format historically suggested and enforced within the UK by the QAA.

The QAA's recent shift of emphasis from teaching oriented to a student oriented approach has been slow (QAA, 2008). This is a noticeably new trend in education which has been largely led by the broader social and technological trends affecting the performance, behaviour and attitudes of students, mainly within higher education. The speed of technological progress and its subsequent incorporation had been resisted by higher educational institutions until recently. This is owed partially to the culture of traditionalism, conformity and adherence to historic habits within the British education system.

The view of traditional methods in Europe being the source of educational success has been a point of national pride for academics and thus the assimilation of new systems like e-learning, distance learning, social media and virtual learning environments has been a much resisted, slow and gradual trend predominantly in higher education. Armstrong (2012 p2) observed that "Learning involves change. However, people often resist information that conflicts with their current beliefs". 
Marketing theory further suggests that technology like any commodity will have its early adopters (in this case young students) and late (older academics who are generally traditional and cultured into more rigid habits).

\subsection{Trends and learning environments}

Emerging trends are often the leading indicators of the future direction of a system, economy, nation or society. The rapid advancement of technology use in education was initially a studentled phenomenon which became widespread to the point that institutions were forced to adapt and alter teaching process to account for social media, virtual media, online forums and personalised learning formats along with new instructional design theories (Wild, Modritscher and Sigurdarson; 2008 p2).

Social trends are the broader stimuli that affect the environment, creating situations within which learning takes place. Trends are acomplex dynamic phenomenon that keeps changing (Prechter, 1999). This creates a multitude of challenges and opportunities. The technological landscape is changing and technology is the driver of change and social trend is the agent of change (Prechter; 1999).Prechter's (1999) socionomics framework defined a theory of the causality of social actionwhich studies the character of trends and events in society. Technological trends may be temporary or permanent, long-term or short-term but have a definite effect on the future.

The education sector is particularly susceptible to technological trends (Rednecker; 2009). Elearning and social media are among the highest growing areas and most significant trends which need to beunderstood and accepted by institutions (Kravick; 2008). E-learning systems within UK universities were initially considered a simple fad which was highly resisted by establishments until the Open University first embraced it which consequently triggered the trend in adopting learning technology and eventually led the QAA to outline a policy on e-learning. The most important trends currently are growth in student demand for Distance Learning (DLE), Virtual Learning (VLE), Adaptive Personal Learning, Learning forums, web2.0, adaptive personalised learning. The number of users and subscribers is growing and forecasted to grow. As Hannafin, Land and Oliver (1999) state that with the expected rise of technology and the abundance of information, new approaches to learning and instruction will be desired.

Authors like Courts and Tucker (2012) advocate embracing technology in order to facilitate improved learning in modern institutions. The benefits claimed by enthusiasts include; improved standards of quality, increased student participation, reducedunethical practice andeasier detection of student unethical practice. Clark and Meyer (2007) propose e-learning as way forward for institutions.

E-learning is defined by the Joint Information Systems Committee as 'learning facilitated and supported through the use of information and communications technology' (QAA Audit paper, 2008 p3). E-learning is considered by proponents to be a way to create a learning environment that best provides for the realisation of learning outcomes.

The current usage of technology in British higher education in its present form is limited to several predominant forms:- use of interactive social forums, recorded delivery of lectures, virtual availability of teaching material, blackboard technology, online assessment marking and feedback and widespread use of chat rooms. This is a minimalist approach to technological integration with very little sophistication, limited usefulness and simplistic mainly due to the cultural resistance towards technology change in UK higher institutions.

\subsection{Impact of Technological TrendsonStudent Performance}


A recent view put forth by Wheeler et al (2013) stresses the role of learning as a driver for social change. Whilst authors like Courts and Tucker (2012) strongly support use of technology to revolutionise teaching it can also be argued that information abundance and new technology becomes a double-edged sword. Widespread social media use has led to the emergence of youth culture driven linguistic patterns, which on the one hand cause the popularisation of words, phrases, sentences which are now becoming colloquial. On the other hand this trend results in the misuse of language and perhaps the deterioration in academic writing skill - noticeable in higher education. Linguistic trends examined closely are identifiable as the early warning sign of social communication. Within academia, the decline in the use of conventional intellectual vocabulary in favour of convenient colloquialism has been influenced greatly by popularisation of social media language. The growing concern felt by noticing the widespread development of colloquial social media language is a social fact. The loss of social etiquette and human interpersonal skills among students entering UK universities is also a growing sentiment shared within academia. An emerging social media culture would see young individuals lacking the ability to have a normal social interaction, engage in a stimulating conversation in favour of social media tweets, text messages or Facebook messages.

This is particularly concerning for some courses like MBA, management science and other courses that rely on development of strong communication, social and interpersonal skills (Armstrong, 2012). Higher failure rates are noted in these subject areas among techno-savvy students not because students are weak in learning content but due to intrinsic inability to interact, communicate or relate to others.

Malik (2011) states that developments in technology, communication and increased interconnectedness affect crowd psychology whichhas far-reaching consequences. One of these noticeable consequences is the decline in language and communication skills among young universitystudents. Social media technology has stimulated a convenient form of commonly abbreviated communication. Student results show decline inbasic spelling, grammar, speech, vocabulary and academic writing ability. This has developed a gradual trend over the last 10 years.

Secondly, linguistic theory suggests that ability to express oneself in complex and sophisticated language aidsthe development of new neural pathways. Currently, it is noticeable that the tendency towards shortening words and abbreviation leads to poor quality of writing in assessments, oral presentation and overall learning which is measurable through annual student result audit reports. The marked increase in UK students' English language difficulties seems an alarming trend.

Thirdly, the growth of information availability and technology reduces the research ability of students by making information overly easy to obtain, making it easier for students to engage in academic malpractice; - plagiarism in particular and lack of appropriate referencing. This is becoming a growing concern for academics involved in the teaching and assessment process. Though it is also arguable that developments in technology make it easier to detect unfair practice, however, there is no evidence that it can prevent plagiarism or improve student learning, so long as the culture in higher education leans more towards teacher orientation than student orientation. Research conducted by McCabe and Trevino (1996, quoted in Armstrong; 2012 pp. 4) showed that unfair practice was greatly reduced when responsibility was transferred from teachers to individual students through use of honour codes. This is worth noting since the mood at UK higher institutions is that students do not demonstrate the maturity or accountability expected of learners at university level education. 
International Journal on Integrating Technology in Education (IJITE) Vol.2, No.3, September 2013

As Armstrong (2012 pp. 7) concluded "The traditional teacher-responsible design for education in universities conflicts with what we know about how people learn. In contrast to natural learning, it substitutes teacher for learner responsibility. Not surprisingly, then, the evidence shows a sharp decline in the effectiveness of universities since 1960".

Based on the overwhelming evidence given this paper switches the role of technology from teacher-orientationto student-orientation and puts the learner back in the lead role and discusses the creation and use of learning systems to serve educational needs as opposed to inventing education to suit technology.

\section{STUDENT-CENTERED APPROACH TO E-LEARNING}

As discussed above, a review of contemporary models, theories and frameworks highlights the weaknesses of conventional teacher-centric approach along with the growing concerns regarding declining standards of student performance and emerging trends. A conceptual framework is therefore required that helps understand the role of e-learning systems as a complex evolving processtaking into account demographic, cultural, technological,intrinsic and extrinsic influences along with quality assurance concerns.It is important to keep in mind the systemic nature of elearning; these influenceslead, affect andimpact student learning in ways that are sometimes unforeseeable.

Research conducted by the UK Quality Assurance Agency (QAA) outlined the importance of developing an integrated strategic approach and establishing coherent institutional frameworks for the delivery and management of e-learning. However, there is little suggestion on how to design an integrated approach appropriate for student oriented learning.

Research done by Tavangarian,Leypold,Nölting andRöser (2004) investigates e-learning as a solution to learning challenges. Taking into account the historic resistance towards technology within British higher education institutions, this article suggests establishing e-learning as a fundamental part of mainstream academic activity. This would involve the creation of an elearning culture which establishes the learning environment as a result of learning rather than merely a process and a system conducive to natural learning.

Biggs and Tang (2011) believe that constructive alignment of learning objectives with curriculum design is about getting students to take responsibility for their own learning, and is seen as a way of engaging students in 'deep' rather than 'surface' learning. This paper goes one step further and suggests that students are given a chance to create a personal learning outcome statementusing key learning verbs.Student-centric learning would entail making students responsible by firstly, giving them a chance to set their own personal learning objective for each module at the beginning of their course. This sets the tone of their study and makes the learner feel more accountable for their own learning and shifts the focus from the teacher to student. In any learning system success is measured by the achievement of learning objectives. Giving the students a chance to set their own individuals objectives gives them a feeling of control over their learning rather than helplessness.

Secondly, giving the students access to interaction with staff as well as fellow students through user-friendly institutional portals. This would entail the development of portals which are easily customisable by students and incorporate student preferred social media in order to make social, personal interaction within an academic framework a more pleasurable, individual experience for students. An e-learning environment must be easily adaptable by students in order to first create increased involvement and second give them a feeling of ownership, emotional stakeholdership and control over their learning process. 
An ideal e-learning framework is one which enables learning to occur at the learner's individual pace while encouraging socialisation to facilitategroup knowledge transfer and instil a strong academic culture, enforcing the values and intellectual habits of successful students. This would entail the use of online intellectual community where new students get to interact with highly successful ones from previous cohorts. Students are naturally inclined to attract and interact with other students of similar situation who share similar values within their own cohorts. These interactions often only facilitates common crowd mentality which gradually conditions them into a social habit or 'comfort zone' situation in which they have few dynamic opportunities to interact with more advanced students or learn new behaviours. An ideal situation would have new students socialised into more desirable behavioural habits by interacting with successful students from earlier cohorts. This could potentially address the growing concern over the trend towards decline in linguistic skill and social etiquette.

The role of academics needs to be reassessed and a new mind-set needs to be adopted by higher education institutions. The role of lecturers, tutors, dissertation supervisors and professors will shift from merely teachers who help students learn and 'assessors of student performance' to 'facilitators of a learning experience'. Indeed, an institution's performance is ultimately judged by the results achieved. Emphasis must shift from the measurement of institutional success by achievement of economic and statistical expectations of results to a more rounded, wholistic approach considering the overall development of individuals' intellectual, interpersonal, verbal as well as social competence. Otherwise, a real danger exists in giving students degrees which have little practical value in the world and do little to reflect the true competence of the degree holder.

E-learning system of quality must be open to change and evolution based on information, changing contexts, and new understandings of the nature of education's challenges. According to Glasser (1990) flexible systems that embrace change through data generation, use and selfassessment are ideal and have a better chance of providing quality education to students. Continuous on-going feedback through assessment and improvement can focus on any or all dimensions of system quality: learners, learning environments, content, process and outcomes (UNICEF; 2000).

According to UNICEF (2000 pp. 7) 'Learning can occur anywhere, but the positive learning outcomes generally sought by educational systems happen in quality learning environments. Learning environments are made up of physical, psychosocial and service delivery elements.'

This view encompasses all aspects of the institution including physical premises, facilities, student activity clubs, societies and lastly, online facilities. Student experience is contingent greatly on all these and other environmental factors along with unforeseeable internal forces and events.

This paper suggests the adoption of technology-friendly culture within UK higher education institutions and letting go of resistance. An evolution in educational technology must also involve a corresponding evolution in educational culture. To this extent it is recommended thattraining academic staff in adopting and using IT systems utilising learning objective based curriculum design would be a necessity.

This paper also recommends encouraging online student feedback in the form of online learning portfolios - especially in Masters' level courses and above. As Armstrong (2012 pp. 6) commented - Students should be encouraged to keep learning logs which could help trace their progress and also provide an audit trail for quality assurance purposes, while providingon-going assessments. 
As Armstrong (2012pp. 5) asserts a learner-oriented approach creates student responsibility while "Efforts to improve the teacher-centered approach reduce learner responsibility. The solution is straightforward: Allow people to take responsibility for their learning."

\section{CONCLUSIONS}

In conclusion, this paper has set out to outline an approach to e-learning environment design that gives the student more responsibility over learning and addresses the growing concern over declining standards brought about by socio-technological trends. The paper concludes that given the direction education is headed towards, it is necessary to develop a new understanding of learning within an e-learning context and implement an approach that best allows the learner to learn through interactive user friendly environment. The paper has also discussed the emerging trends in higher education and the way forward for UK higher education. It has considered the benefits and challenges posed by technology and conclude that technology needs to be embraced by institutions, not merely on a surface level but as a mind-set and culture. Resistance to technology needs to be addressed and a culture change is necessary. A strategy is outlined for the implementation of e-learning as a solution to what the article considers 'learning problems'.

\section{ACKNOWLEDGEMENTS}

The author would like to thank the editors at IJITE, the Associate Dean of Kaplan Holborn College Department of Business, colleagues in the faculty and quality assurance for all the support, help and assistance in composing this article. Special thanks to Professors Lima and Moniz for their invaluable time and guidance without which this paper would not be a reality.

\section{REFERENCES}

[1] Bandura, A., \& Walters, R. H. (1963)Social learning and personality development. New York: Holt, Rinehart, \& Winston.

[2] Bassett, D.S., Meyer-Lindenberg, A., Achard, S., and Bullmore, E. (2006) "Adaptive reconfiguration of fractal small-world human brain functional networks", vol. 103 no. 51, Proceedings of the National Academy of Sciences of the United States of America, December 11.

[3] Biggs, J. and Tang, C., (2011)Teaching for Quality Learning at University, 4th edn, New York,McGraw-Hill.

[4] Carrell, S. E. \&West , J. E. (2010) "Does professor quality matter? Evidence from random assignment of students to professors," Journal of Political Economy, 118 (3), pp.409-432.

[5] Cazden, C. (2000)“'In Ensuring Learning Takes Place: A focus on literacy”, Paper prepared for Human Development Week, World Bank, Washington, D.C. March.

[6] Chambers, J. (2000) In Pape, L. Online education: The internet's killer app http://concord.org/library/2000spring/killerapp.html

[7] Clark, R. C., Mayer, R. E. (2007) eLearning and the Science of Instruction. San Francisco: Pfeiffer.

[8] Clayson, D. E. (2009) "Student evaluations of teaching: Are they related to what students learn? A meta-analysis and review of the literature," Journal of Marketing Education, 31 (1), pp. 16-30.

[9] Colby, J. (2000) "Learning Outcomes in International Context". Paper presented at the Annual Meeting of the Comparative and International Education Society, San Antonio, Texas, March.

[10] Courts, B., \& Tucker, J. (2012) "Using Technology To Create A Dynamic Classroom Experience". Journal of College Teaching \&Learning, 9(2), pp. 121-128.

[11] Craig, H., Kraft, R., and du Plessis, J. (1998) "Teacher development: Making an impact",Academy for Educational Development, ABEL Clearinghouse for Basic Education. Washington, D.C. 
International Journal on Integrating Technology in Education (IJITE) Vol.2, No.3, September 2013

[12] Crossick, G., (2010)“The growth of private and for-profit higher education providers in the UK".Universities UK. Accessible at: www.universitiesuk.ac.uk/Publications/Pages/Privateandforprofitproviders.aspx

[13] Denny, C. (2000) "Internet promises salvation — or an even bigger knowledgegap", The Guardian Feb 1 .

[14] Geiger, R., (1996) "Diversification in US higher education: historical patterns and current trends", in Meek, V., Goedegebuure, L., Kivinen, O., \&Rinne, R., (1996)The Mockers and the Mocked: Comparative Perspectives on Diversity, Differentiation and Convergence in Higher Education(eds).

[15] Henke, K., (2010) "A model for memory systems based on processing modes rather than consciousness", Nature Reviews Neuroscience 11, 523-532.

[16] Hull, C. L. (1943) Principles of Behavior: An Introduction to Behavior Theory. New York: Appleton-Century-Crofts.

[17] Koper, R., and Tattersall, C. (2005)Learning Design. Berlin: Springer.

[18] Kravcik, M. (ed.) (2008) "Current and Future Perspectives for Personalized Adaptive Learning”. Deliverable D1.13 of the Prolearn Network of Excellence.

[19] Laudon, K.C., and Laudon, J.P., (2012) Management Information Systems: Managing the Digital Firm, $12^{\text {th }}$ ed. New York, Prentice Hall.

[20] Levy, D.C., (1986) Higher education and the state in Latin America: private challenges to public dominance, University of Chicago Press, Chicago.

[21] Malik. C, (2011) "Ahead of Change: How Crowd Psychology and Cybernetics Transform the Way We Govern", accessible on http://www.robertprechter.com/.

[22] Pavlov, I. P. (1897) The Work Of The Digestive Glands. London: Griffin.

[23] Pellionisz, A.J, (1988) "Vistas from Tensor Network Theory: A Horizon from Reductionalist Neurophilosophy to the Geometry of Multi-Unit Recordings", In: Computer Simulation in Brain Science (ed. by R. Cotterill), Cambridge University Press, pp. 44-73.

[24] Pellionisz, A.J, (1988) "Tensor Geometry: A Language of Brains and Neurocomputers. Generalized Coordinates in Neuroscience and Robotics”, In: Neural Computers (NATO Advanced Science Institutes Series, F), Computers and Systems Sciences, Vol. 41, (ed. by R. Eckmiller and C. von Malsburg), Springer Verlag, Berlin pp. 381-391.

[25] Pituch, K., and Lee, Y. (2006)“The Influence of System Characteristics on E-learning Use.”Computers \& Education, 47, pp. 222-244.

[26] Pilikian, H.I. (2011) "Discovery of Linguistic Fossils and the Origin of Modern Thought", Conference presentation held at Birkbeck College, University of London Open Discussion Society.

[27] Poirier, P., and Chicoisne, G. (2006)“A Framework for Thinking about Distributed Cognition”, In Harnad\&Dror (Eds.), Special Issue on Distributed Cognition,Pragmatics \& Cognition, 14(2), Amsterdam/Philadelphia: John Benjamins Publishing.

[28] Prechter,R.R. (2011)“The Wave Principle of Human Social Behaviour", New Science of Socionomics, Accessible: http://www.socionomics.net/2012/09/social-mood-impels-feelings-ofcertainty-and-uncertainty/\#ixzz2bMsoLeVD.

[29] Redecker, C., (2009) "Review of Learning 2.0 Practices: Study on the Impact of Web 2.0 Innovations on Education and Training in Europe",JRC Scientific and Technical Report. (EUR $23664 \mathrm{EN}$ - 2009).

[30] Sheldrake, R. (1981) “A New Science of Life: The Hypothesis of Formative Causation”, Park Street Press(March 1, 1995).

[31] Skinner, B. F. (1971)Beyond Freedom and Dignity, New York: Knopf.Inc.

[32] Skinner, B. F. (1948) Walden Two, New York: Macmillan.

[33] Tavangarian, D.,Leypold, M., Nölting K., Röser, M.,(2004)“Is e-learning the Solution for Individual Learning?",Journal of e-learning.

[34] Thorndike, E. L. (1905)TheElements of Psychology, New York: A. G. Seiler.

[35] UNICEF (2000)“The International Working Group on Education Florence, Italy”, Working Paper Series, June 2000.

[36] Watson, J. B. (1913) "Psychology as the Behaviorist views it", Psychological Review, 20, 158178.

[37] Watson, J. B. (1930) "Behaviorism", (revised edition), University of Chicago Press.

[38] Watson, J. B., \&Rayner, R. (1920)“Conditioned emotional reactions”,Journal of Experimental Psychology, 3, 1, pp. 1-14. 
International Journal on Integrating Technology in Education (IJITE) Vol.2, No.3, September 2013

[39] Wheeler, L., Wong, S., Farrell, J.and Wong, I.,(2013)“Learning as a driver for change”, Australian Centre of Excellence for Local Government, Sydney, viewed 21 Sep 2013, accessible: http://www.acelg.org.au/news-detail.php?id=321.

[40] Wild, F.,Mdritscher, F., and Sigurdarson, S., (2008),"Designing for change: mash-up personal learning environments". eLearning Papers, 9, accessible at: http://www.elearningpapers.eu/index.php?page $=$ doc\&doc id=11939\&doclng $=6$

\section{Author}

Chad Manian is an Interdisciplinary Researcher and

lecturer in E-Business and Entrepreneurship at Kaplan Holborn College UK. 